\title{
Beclabuvir can inhibit the RNA-dependent RNA polymerase of newly emerged novel coronavirus (SARS-CoV-2)
}

\author{
Kunal Dutta ${ }^{1,}{ }^{*}$, Sergey Shityakov ${ }^{2,6,7,8}$, Olga Morozova ${ }^{3,9}$, Ibrahim Khalifa ${ }^{4}$, Jin \\ Zhang ${ }^{11}$, Wei Zhu ${ }^{10}$, Amiya Kumar Panda ${ }^{5}$, Chandradipa Ghosh ${ }^{1, *}$
}

${ }^{1}$ Department of Human Physiology, Vidyasagar University, Midnapore-721102, West Bengal, India

${ }^{2}$ Department of Bioinformatics, Biocenter, University of Würzburg, Würzburg, Germany

${ }^{3}$ Laboratory of Molecular Epidemiology of Viral Infections, I.N. Blokhina Nizhny Novgorod Research Institute of Epidemiology and Microbiology, 603950 Nizhny Novgorod, Russia federation

${ }^{4}$ Food Technology Department, Faculty of Agriculture, 13736 Moshtohor, Benha University, Egypt

${ }^{5}$ Department of Chemistry and Chemical technology, Vidyasagar University, Midnapore-721102, West Bengal, India

${ }^{6}$ Department of Anesthesia and Critical Care, University Hospital Würzburg, Würzburg, Germany

${ }^{7}$ Department of Psychiatry and Mind-Body Interface Laboratory (MBI-Lab), China Medical University Hospital, Taichung, 40402 Taiwan

${ }^{8}$ College of Medicine, China Medical University, Taichung, 40402 Taiwan

${ }^{9}$ Lobachevsky State University of Nizhny Novgorod, 603950 Nizhny Novgorod, Russian Federation

${ }^{10}$ College of Food Science and Technology, Huazhong Agricultural University, Key Laboratory of Environment Correlative Food Science (Huazhong Agricultural University), Ministry of Education, Wuhan 430070, China., Wuhan 430070, China

${ }^{11}$ Institute of Groundwater and Earth Sciences, Jinan University, 601 W. Huangpu Avenue, 510632 Guangzhou, China 


\section{${ }^{*}$ Correspondence:}

Prof. Chandradipa Ghosh

E-mail:ch_ghosh@mail.vidyasagar.ac.in

Mr. Kunal Dutta

E-mail: Kunal_lifesc@mail.vidyasagar.ac.in

\section{Abstract}

Recent emergence of novel coronavirus (SARS-CoV-2) all over the world has resulted more than 33,106 global deaths. To date well-established therapeutics modules for infected patients are unknown. In this present initiative, molecular interactions between FDA-approved antiviral drugs against the Hepatitis-C virus (HCV) have been investigated theoretically against the RNA-dependent RNA polymerase (RdRp) of SARS-CoV-2. HCV and SARS-CoV-2 are both +SsRNA viruses. At $25^{\circ} \mathrm{C}$ beclabuvir, a non-nucleoside inhibitor of the RdRpHcv can efficiently bind to RdRp SARS-Cov-2 $\left(\Delta \mathrm{G}_{\text {AutoDock }}=-9.95 \mathrm{kcal} \mathrm{mol}^{-1}\right)$ with an inhibition constant of $51.03 \mathrm{nM}$. Both the $\Delta \mathrm{G}_{\text {London }}$ and $\Delta \mathrm{G}_{\mathrm{GBV}} / \mathrm{WSA}$ values were -9.06 and $-6.67 \mathrm{kcal} \mathrm{mol}^{-1}$, respectively for binding of beclabuvir to RdRpSARS-Cov-2. In addition, beclabuvir has also shown better binding free energy with RdRpsARs-Cov-2 $\left(\Delta G_{\text {vina }}=-8.0 \mathrm{kcal} \mathrm{mol}^{-1}\right)$ than that observed with the Thumb 1 domain of $\operatorname{RdRp}$ Hсv $\left(\Delta G_{\text {vina }}=-7.1 \mathrm{kcal} \mathrm{mol}^{-1}\right)$. InterProScan has suggested the RNA-directed 5'-3' polymerase activity exists within $549^{\text {th }}$ to $776^{\text {th }}$ amino acid residues of RdRpsaRs-Cov-, where the major amino acid residues interacting being 1591, Y621, C624, D625, A690, N693, L760, D762, D763 and E813-N817. Molecular interaction suggests occupancy of beclabuvir inside the active site environment of the RdRpsaRs-Cov-2, the enzyme essential for viral RNA 
synthesis. In conclusion, results suggest beclabuvir may serve as an anti-SARS-CoV2 drug.

\section{Keywords}

Novel coronavirus (SARS-CoV-2), RdRp, HCV, beclabuvir, in silico, molecular docking

\section{Introduction}

The newly emerged novel coronavirus (SARS-CoV-2) was first reported from patients with connection history at the Wuhan Seafood market in Hubei province of China in December 2019. Clinical symptoms of the infection caused by this newly arrived pneumonia virus were similar to the previously emerged severe acute respiratory syndrome coronavirus (SARS-CoV) and Middle East respiratory syndrome coronavirus (MERS-CoV) infections [1]. As of $30^{\text {th }}$ March, 2020, confirmed 6,93,224 positive cases have been registered with 33,106 global deaths out of which 3,310 deaths occurred in China and 10,781 deaths in Italy [2]. The super-spreader feature of SARS-CoV-2 is continuously increasing the confirmed positive cases and so far the estimated global death rate is $4.77 \%$ [2]. Social distancing and travel restrictions have been implemented globally as non-pharmaceutical measures to control the fire of the outbreak [3]. In the beginning, governments of different nations evacuated their citizens from China and initiated quarantine protocols to save them. In certain serious areas of China and Italy citizens have been locked-down in their homes as they are at the fourth stage of the Pandemic [4]. Due to the severity of virus outbreak, the World Health Organisation (WHO) has declared this new novel coronavirus outbreak as a Pandemic [5]. Flowing China, Italy has now become the new epicenter of SARS-CoV- 
2 infection where 97,689 positive cases and 10,781 (11.03\%) deaths of SARS-CoV2 infection have been recorded with in a few weeks [6].

In the South-East Asian region, India ranks as the third most-affected country after Indonesia and Thailand respectively [2]. India, has reported 1071 confirmed positive cases and 29 deaths from SARS-CoV-2 infection as of $30^{\text {th }}$ March 2020. Maharastra, the state of India, has become the most affected state, which indicates its vulnerbility to infectious diseases. Patients with an international travel history and symptoms of viral-flu were suspected and tested with expensive SARS-CoV-2 test costing nearly $\$ 67$. The respiratory illness caused by this new SARS-CoV-2 collectively called, coronavirus disease 2019 (COVID-19) [2]. In the very beginning of 2020, and the new decade, COVID-19 has impacted on the global economy and resulted in a near shutdown of the global equity market, for example on $19^{\text {th }}$ February 2020 Tesla, Inc. ended the day down by $17 \%$, which is the second-worst drop ever. The global airline industry has also been badly knocked-down by the COVID-19 global Pandemic.

Coronavirus is a member of a large virus family, the coronaviridae and subfamily orthocoronavirinae which usually causes respiratory illness to humans and animals [7]. Soon after the first report of the outbreak, a research group lead by Dr. Zhang at Fudan University, China has sequenced the complete genome which is nearly 30,000 nucleotides long and encodes 10 proteins (MN908947.3), [8]. Like SARS-CoV, the newly emerged novel coronavirus (SARS-CoV-2) is about $60-140 \mathrm{~nm}$ in diameter and has trimeric spike glycoprotein (S), membrane capsid protein (M), small membrane protein, viral nucleoprotein $(\mathrm{N})$ and an RNA dependent RNA polymerase (RdRp), which are essential for virus replication [9]. Usually, entry of human coronavirus is mediated by interactions of spike glycoprotein with angiotensin 
converting enzyme 2 (ACE2), aminopeptidase $\mathrm{N}$ (AmoPep-N) and dipeptidyl peptidase 4 (DPP-4), $[10,11]$. The new SARS-CoV-2 is phylogenetically closer to known coronavirus strains of bat-SL-CoVZC45 and bat-SL-CoVZXC21 than SARSCoV [12].

Research has suggested nonstructural proteins (NSPs) and structural proteins (SPs) of SARS-CoV-2 have linked a function. For example, NSP can block the host innate immune response and the viral envelope promotes viral assembly and release [13]. However, optimal therapeutic drug for treating the infected patients are still unknown. In the entire genome of SARS-CoV-2, 93 mutations were detected out of which 29 mis-sense mutations were found in the ORF1ab polyprotein that encodes the RdRp [13]. SARS-CoV-2 and HCV, are both +ssRNA viruses and have $22.22 \%$ sequence similarities between their RdRps. In this study, an attempt has been made to identify the most efficient inhibitor of RdRpsars-Cov-2 with the help of computational approaches and by screening the inhibitory properties of commonly used RdRpнсv (NS5B) inhibitors.

\section{Methods}

\section{Data sampling and analysis}

The nucleotide sequences of SARS-CoV-2 were originally retrieved from NCBIVirus, Accession Number: MN908947.3. Multiple sequence alignment was performed using MEGA-v2016, [14]. The amino acid sequence of the viral RdRp was scanned for identification of known functional domains/motifs using InterPro Scanner [15]. Homology modeling of the RdRp was carried out using SwissModel and quality was checked using PROCHECK [16]. Rigid-body molecular docking between several 
established antiviral drugs and RdRpsARs-Cov-2 was carried out using AutoDock (v4.2), [14]. Additionally, implicit solvation was performed using Molecular Operating Environment (v9.10) [14]. Molecular docking studies were visualized using PyMol [14]. Molecular interactions of different antiviral drugs i.e., beclabuvir, tegobuvir, dasabuvir, deleobuvir, setrobuvir, radalbuvir, lomibuvir, remdesivir, uprifosbuvir and favipiravir were investigated with the RdRpsars-Cov-2.

\section{Results}

The amino acid sequences of the viral RdRp were compared by multiple sequence alignment in order to understand the evolutionary difference among with previously reported coronavirus strains. Dissimilarities were prominent among coronavirus strains isolated from a different source of host organisms (Figure 2). The RdRp (PDB:6NUR) of previously emerged SARS-CoV was used as a template in obtaining the homology model of the RdRp [17]. The homology model of RdRp showed 96.35 \% sequence similarities with 6NUR. The GMQE and QMEAN were 0.83, and 0.71, respectively, where $98.1 \%$ of the amino acid residues were within Ramachandran favored zone which combinedly suggest the high quality of the homology model. Molecular docking studies are summarised in Table 1. Data presented in Table 1 suggest thermodynamically favoured binding properties of beclabuvir and other antiviral drugs with the RdRp of SARS-CoV-2. Among all the aniviral drugs studied beclabuvir showed the best $\Delta G_{\text {AutoDock }}$ of $-9.95 \mathrm{kcal} \mathrm{mol}^{-1}$ followed by tegobuvir $\left(-9.68 \mathrm{kcal} \mathrm{mol}^{-1}\right)$ and dasabuvir $\left(-9.38 \mathrm{kcal} \mathrm{mol}^{-1}\right)$. However, best $\Delta$ GLondon was found for lomibuvir $\left(-10.96 \mathrm{kcal} \mathrm{mol}^{-1}\right)$ followed by setrobuvir $(-10.52$ $\left.\mathrm{kcal} \mathrm{mol}^{-1}\right)$ and dasabuvir $\left(-10.38 \mathrm{kcal} \mathrm{mol}^{-1}\right)$. Setrobuvir also displayed best $\Delta \mathrm{GGBVI}_{\mathrm{G}}$ 
wsA $\left(-7.48 \mathrm{kcal} \mathrm{mol}^{-1}\right)$ followed by remdesivir $\left(-7.36 \mathrm{kcal} \mathrm{mol}^{-1}\right)$, radalbuvir $(-7.36 \mathrm{kcal}$ $\left.\mathrm{mol}^{-1}\right)$ and dasabuvir $\left(-6.68 \mathrm{kcal} \mathrm{mol}^{-1}\right)$. Allthough, lowest inhibition constant is offred by remdesivir (18.12 $\mathrm{nM})$ but, best $\Delta \mathrm{G}_{\text {AutoDock }}\left(-9.95 \mathrm{kcal} \mathrm{mol}^{-1}\right)$ and inhibition constant (51.03 nM) is offered by beclabuvir with $\Delta G_{\text {London }}$ and $\Delta G_{G B V I}$ wSA of $-9.06 \mathrm{kcal} \mathrm{mol}^{-1}$, $-6.67 \mathrm{kcal} \mathrm{mol}^{-1}$ respectively (Table 1 ). Currently, WHO is conducting a clinical trial program, called global "Solidatory Trial", in which only remdesvir is included.

\section{Discussion}

Upon entry inside the host cell, viral RdRp enables multiplication of the +SsRNA virus $[18,19]$ and eventually the consequences of the viral infection in the host [17]. Thus, RdRp has always been a favorite drug target in antiviral therapeutic research [20]. Nowadays, different antiviral strategies such as, capping the virus particle which enables tethering it into the host epithelial cell membrane [21], designing a DNA vaccine against the major glycoproteins displayed outside the viral capsid protein [22], targeted delivery of miRNA [23], combination antiviral drug therapy [24], etc are commonly employed for therapeutic purposes. Results of the present study suggest that ATP binding domain and RNA-directed 5'-3' polymerase activity of the RdRp exist within $549^{\text {th }}$ to $776^{\text {th }}$ amino acid residues (GO:0003968) and this stretch of amino acids is crucial for RNA synthesis (Figure 3). Beclabuvir is a non-nucleoside polymerase inhibitor that potentially inhibit nonstructural protein 5B (NS5B) of HCV [25]. Previous studies, including phase 3 clinical trials have suggested beclabuvir have a high response rate at post-treatment week [26, 27]. Moreover, the pharmacokinetic, efficiency and tolerability were also reported very favorable [28]. Upon intracellular uptake beclabuvir allosterically binds to the non-catalytic Thumb 1 site (Figure 4) of 
viral RdRp which slowdown the RNA synthesis process [25]. However, in the case of RdRpsaRs-Cov-2 beclabuvir occupies the active site environment (ASE), (Figure 5) is essential for the RNA-dependent polymerase activity $[18,19]$ ). The major interacting residues were I591, Y621, C624, D625, A690, N693, L760, D762, D763 and E813N817 (Figure 1). Moreover, beclabuvir also showed better binding free energy $\left(\Delta \mathrm{G}_{\mathrm{vina}}\right.$ $\left.=-8.0 \mathrm{kcal} \mathrm{mol}{ }^{-1}\right)$ for $\operatorname{RdRphcv}\left(\Delta \mathrm{G}_{\text {vina }}=-7.1 \mathrm{kcal} \mathrm{mol}^{-1}\right)$. Properties of molecular interaction of beclabuvir and other FDA approved antiviral drugs against HCV infection are summarized in Table 1 which could also be effective to use against SARS-CoV-2 infection. This preliminary study may be contributory towards the anti-epidemic efforts against the newly emerged SARS-CoV-2 [9, 29-31] and may help to shorlist antiviral drugs against SARS-CoV-2 for clinical trials.

\section{Conclusion}

Throughout history, the human race had been challenged by multiple of globalpandemics. However, with the advancement of medical science and at the age of Artificial Intelligence, global health disaster of this scale, probablly would not be difficult to manage. However, the things that matter most are the time and the supply of resources. As reported by WHO, the original outbreak began in December-2019 and within three months, global death toll due to SARS-CoV-2 has reached the tragic milestone of 26,000 . In conclusion, this rapid study suggests beclabuvir, and other commonly used antiviral drugs for HCV could be utilized as anti-SARS-CoV-2 drugs to control the devastation of the outbreak. However, more studies are required before the practical use of these antiviral drugs. 


\section{Acknowledgement}

Council of Scientific and Industrial Research (CSIR), Govt. of India, New Delhi, India is also sincerely acknowledged by K.D. for Senior Research Fellowship (SRF), sanction letter no. 09/599 (0082) 2K19 EMR-Z. All co-authors are sincerely ackowledged for different data resources created especially for SARS-CoV-2.

\section{Declaration of interests}

The author declares no competing financial interests.

Figure Legends

Figure 1. Molecular interaction between beclabuvir and RNA dependent RNA polymerase of newly emerged novel coronavirus (RdRpsars-Cov-2). A. Major interacting amino acid residues which occupy the catalytic site of RdRpsaRs-cov2. B. Binding pose of beclabuvir with RdRPsars-Cov-2.

Figure 2. Phylogenetic position of the RdRpsaRS-CoV-2. Tree was constructed using multiple sequence alignment followed by neighbor-joining method with 1000 bootstraps replicates. The alpha-numeric values at right indicate Protein Data Bank accession ID. The numeric values at the top of the tree branch indicate bootstraps replicate values. 
Figure 3. Protein domain/motif analysis of the RdRpsars-Cov-2. The yellow highlighted region indicates the catalytic site (RNA-directed RNA-polymerase activity) of the RdRpsars-Cov-2.

Figure 4. Molecular interaction between beclabuvir and NS5BHCv. Beclabuvir binds at the thumb domain (blue) of NS5BHCV.

Figure 5. Binding site of RdRpsars-Cov-2 for commonly used antiviral drugs. A. Binding posture of beclabuvir at the catalytic site of RdRpsars-Cov-2. B. Overlapped binding sites of antiviral drugs with RdRpsaRs-Cov-2 (Molecular surface mainly in blue-gray indicates the binding site).

Table 1. Summary of molecular docking properties among antiviral drugs and RdRpsars-CoV-2. 


\section{FIGURE 1}

A.

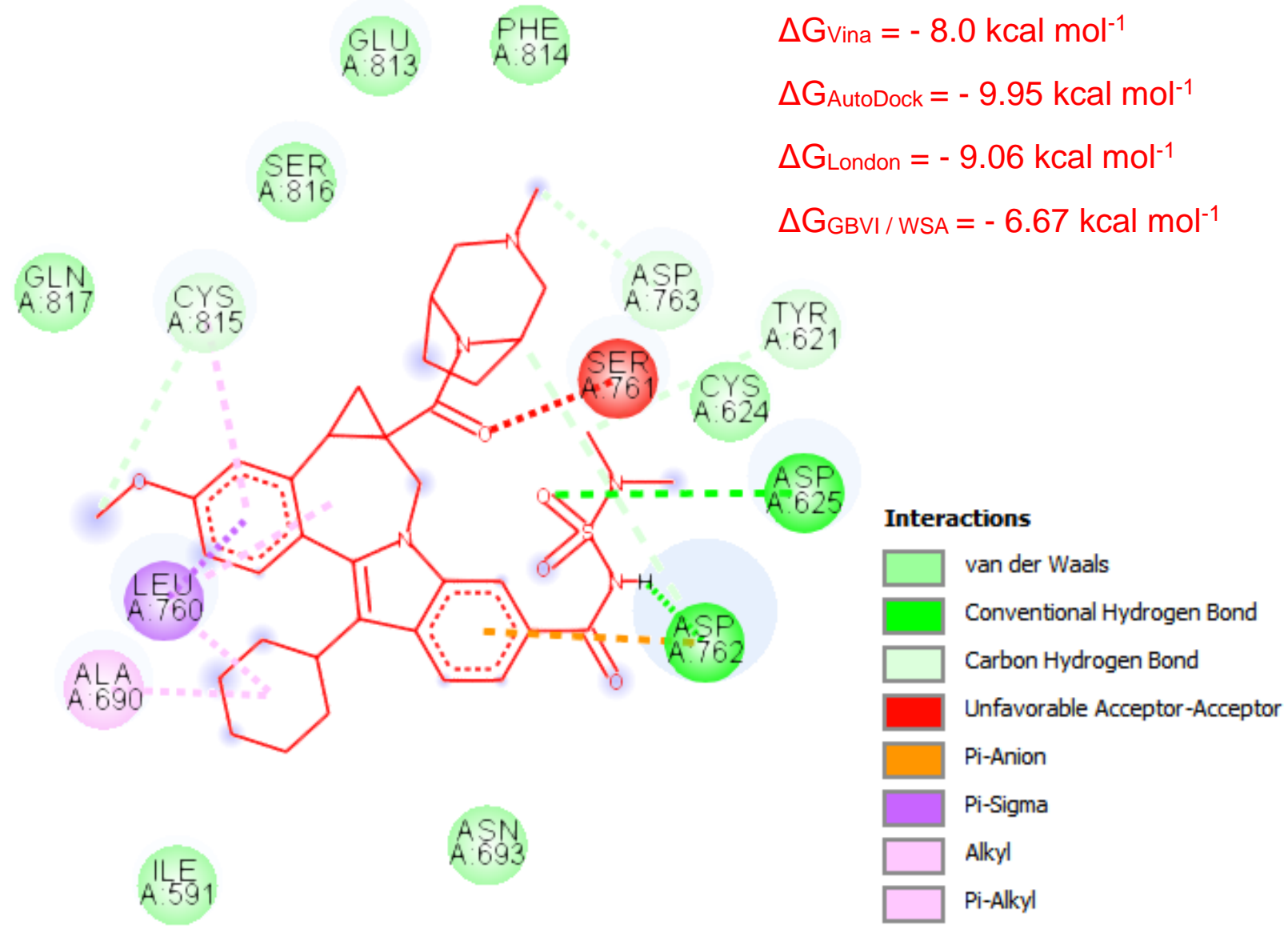




\section{FIGURE 1}

B.

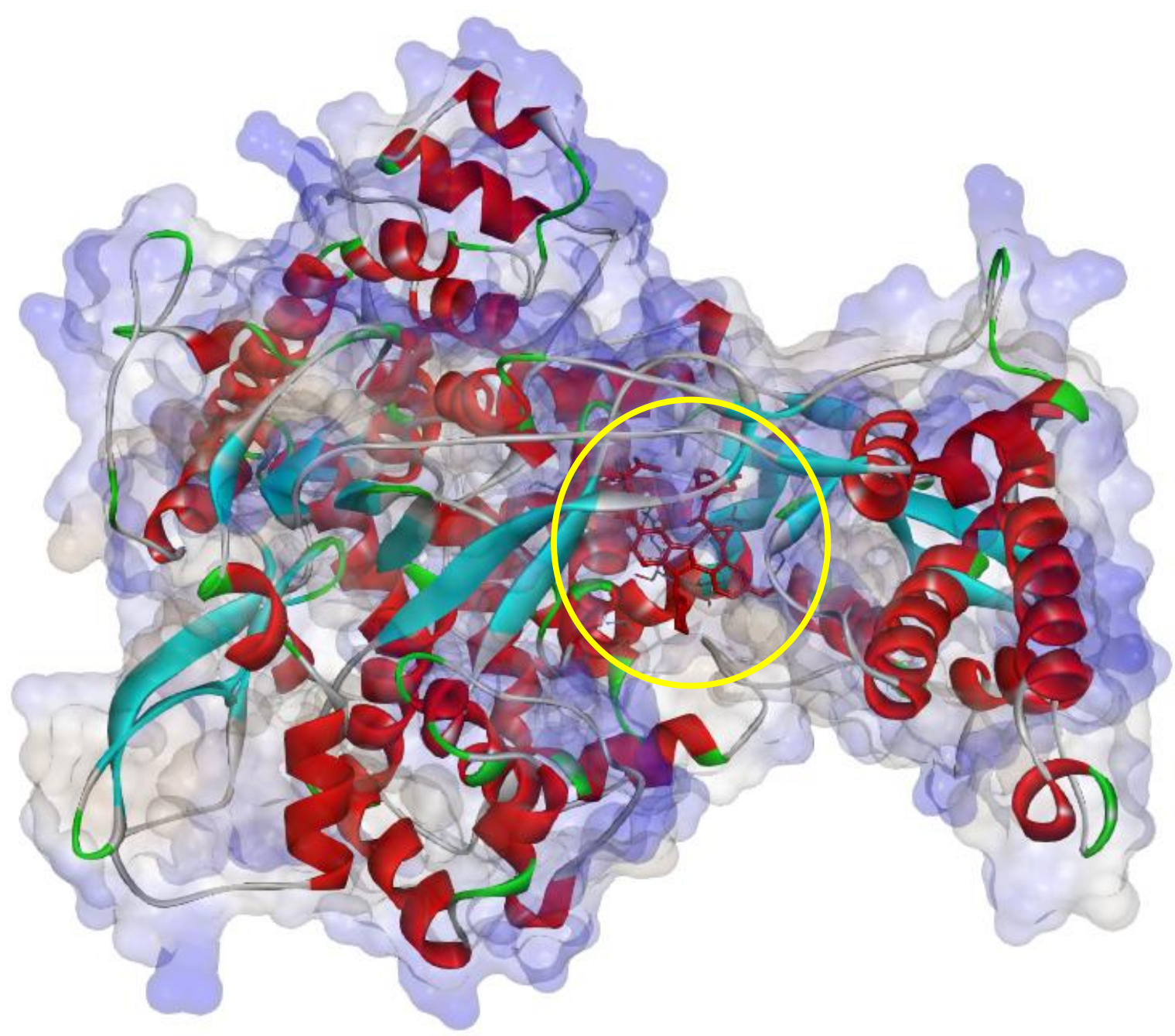




\section{FIGURE 2}

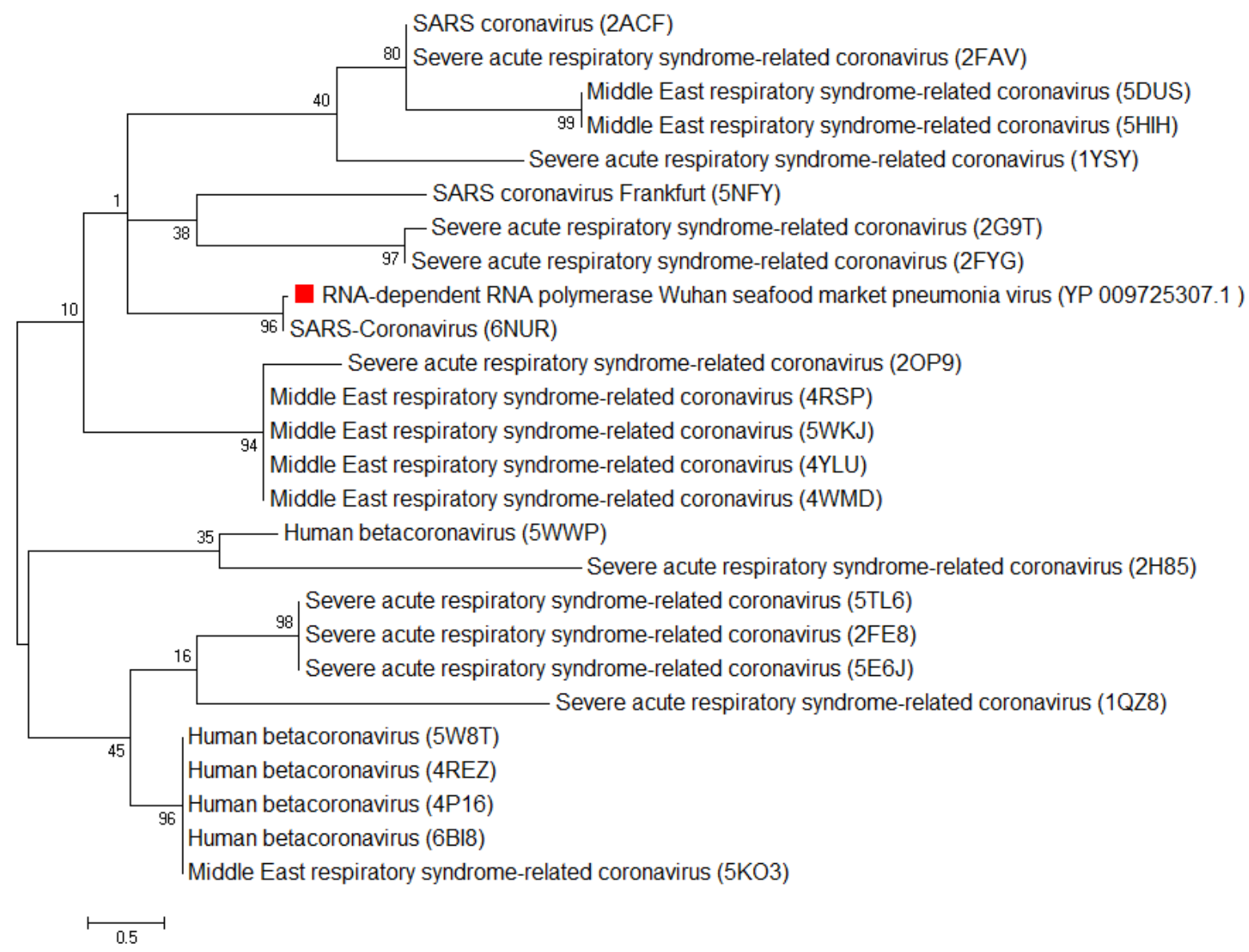




\section{FIGURE 3}

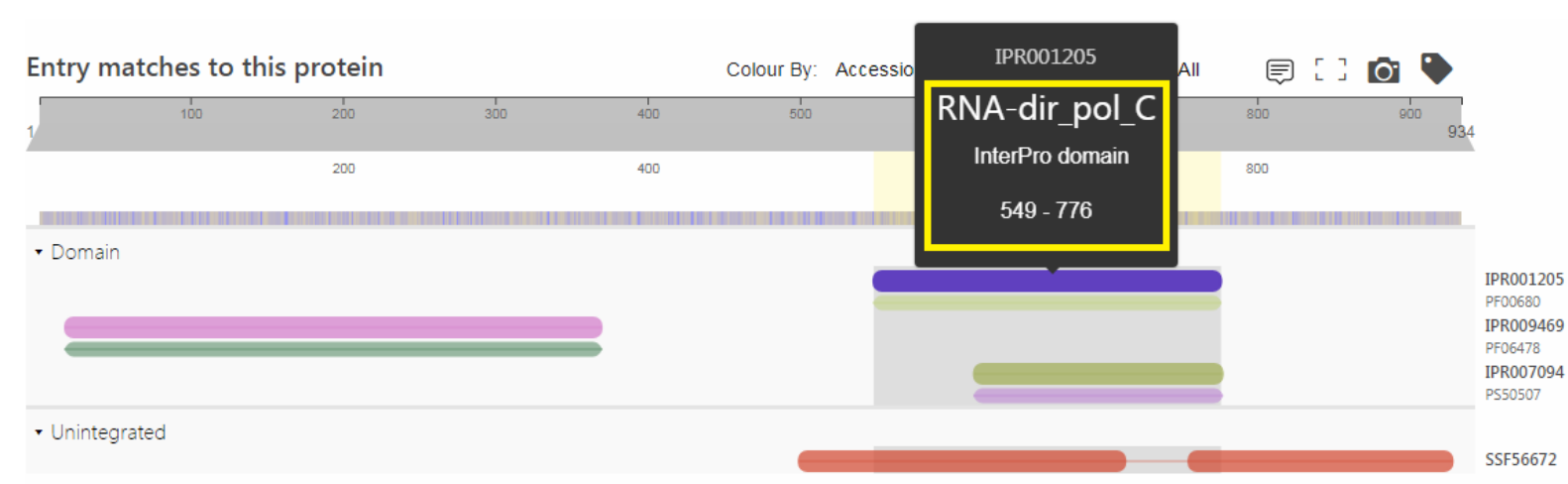

GO terms

Biological Process

Molecular Function

Cellular Component

- transcription, DNA-templated (GO:0006351)

- RNA binding (GO:0003723) $\triangle$

None

- viral RNA genome replication (GO:0039694)

- RNA-directed 5'-3' RNA polymerase activity (GO:0003968)

- ATP binding (GO:0005524)【 


\section{FIGURE 4}
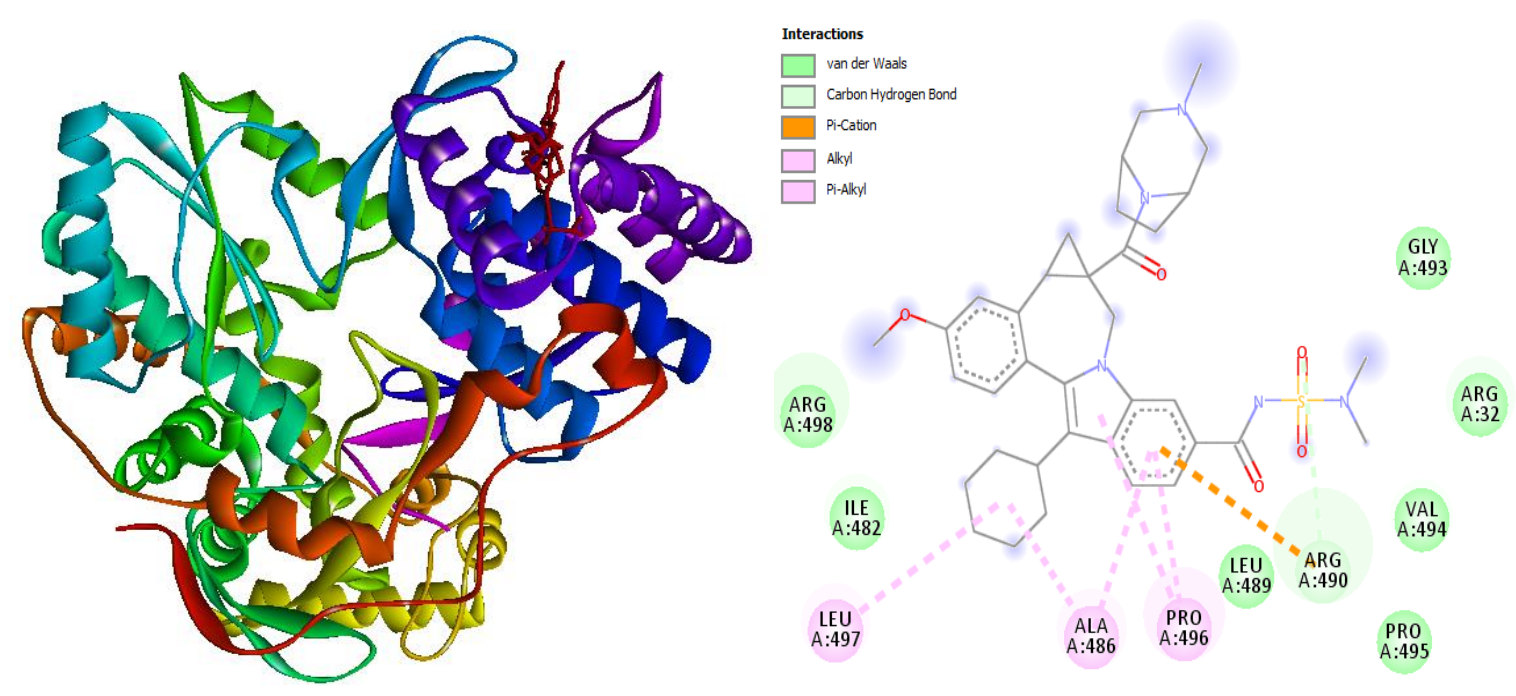

$\Delta G_{\text {Vina }}=-7.1 \mathrm{kcal} \mathrm{mol}^{-1}$ 


\section{FIGURE 5}

A.

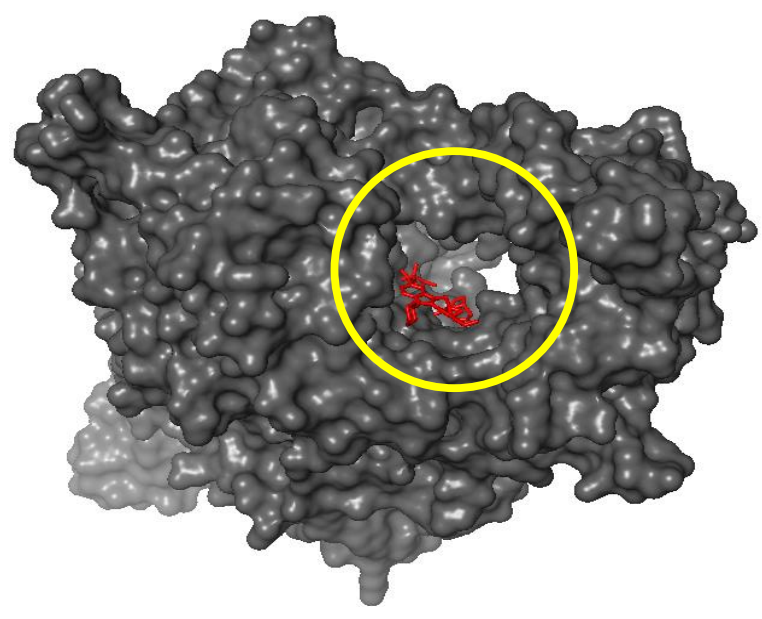

B.

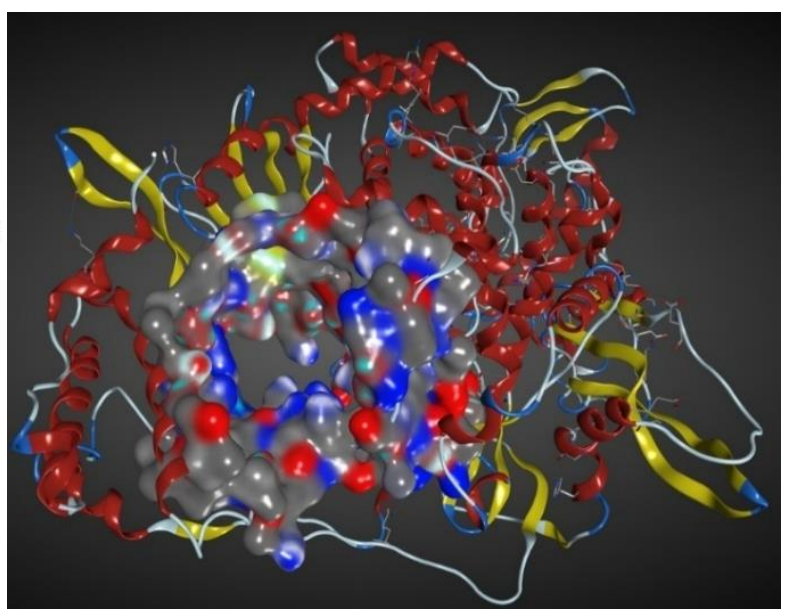




\section{References}

[1] Zou L, Ruan F, Huang M, Liang L, Huang H, Hong Z, et al. SARS-CoV-2 viral load in upper respiratory specimens of infected patients. New England Journal of Medicine. 2020.

[2] WHO. Coronavirus disease (COVID-2019) situation reports. Geneva: WHO; 2020.

[3] Wilder-Smith A, Freedman D. Isolation, quarantine, social distancing and community containment: pivotal role for old-style public health measures in the novel coronavirus (2019-nCoV) outbreak. Journal of Travel Medicine. 2020;27:taaa020.

[4] Fanelli D, Piazza F. Analysis and forecast of COVID-19 spreading in China, Italy and France. arXiv preprint arXiv:200306031. 2020.

[5] Gates B. Responding to Covid-19-A Once-in-a-Century Pandemic? New England Journal of Medicine. 2020.

[6] Porcheddu R, Serra C, Kelvin D, Kelvin N, Rubino S. Similarity in Case Fatality Rates (CFR) of COVID-19/SARS-COV-2 in Italy and China. The Journal of Infection in Developing Countries. 2020;14:125-8.

[7] Van Der Hoek L, Pyrc K, Jebbink MF, Vermeulen-Oost W, Berkhout RJ, Wolthers $\mathrm{KC}$, et al. Identification of a new human coronavirus. Nature medicine. 2004;10:368-73

[8] Wu F, Zhao S, Yu B, Chen Y-M, Wang W, Song Z-G, et al. A new coronavirus associated with human respiratory disease in China. Nature. 2020;579:2659.

[9] Zhu N, Zhang D, Wang W, Li X, Yang B, Song J, et al. A novel coronavirus from patients with pneumonia in China, 2019. New England Journal of Medicine. 2020. 
[10] Li W, Moore MJ, Vasilieva N, Sui J, Wong SK, Berne MA, et al. Angiotensinconverting enzyme 2 is a functional receptor for the SARS coronavirus. Nature. 2003;426:450-4.

[11] Raj VS, Mou H, Smits SL, Dekkers DH, Müller MA, Dijkman R, et al. Dipeptidyl peptidase 4 is a functional receptor for the emerging human coronavirusEMC. Nature. 2013;495:251-4.

[12] Lu R, Zhao X, Li J, Niu P, Yang B, Wu H, et al. Genomic characterisation and epidemiology of 2019 novel coronavirus: implications for virus origins and receptor binding. The Lancet. 2020;395:565-74.

[13] Phan T. Genetic diversity and evolution of SARS-CoV-2. Infection, Genetics and Evolution. 2020:104260.

[14] Dutta K, Shityakov S, Khalifa I, Mal A, Moulik SP, Panda AK, et al. Effects of secondary carbon supplement on biofilm-mediated biodegradation of naphthalene by mutated naphthalene 1, 2-dioxygenase encoded by Pseudomonas putida strain KD9. Journal of hazardous materials. 2018;357:187-97.

[15] Hunter S, Apweiler R, Attwood TK, Bairoch A, Bateman A, Binns D, et al. InterPro: the integrative protein signature database. Nucleic acids research. 2009;37:D211-D5.

[16] Dutta K, Nag K, Booth V, Smyth E, Dueck H, Fritzen-Garcia M, et al. Paradoxical Bactericidal Effects of Hydrophobic Lung Surfactant Proteins and Their Peptide Mimics Using Liposome Molecular Trojan. Journal of oleo science. 2018:ess18026.

[17] Kirchdoerfer RN, Ward AB. Structure of the SARS-CoV nsp12 polymerase bound to nsp7 and nsp8 co-factors. Nature communications. 2019;10:1-9. 
[18] Shu B, Gong P. Structural basis of viral RNA-dependent RNA polymerase catalysis and translocation. Proceedings of the National Academy of Sciences. 2016;113:E4005-E14.

[19] Fouad AM, Soliman H, Abdallah ES, Ibrahim S, El-Matbouli M, Elkamel AA. Invitro inhibition of spring viremia of carp virus replication by RNA interference targeting the RNA-dependent RNA polymerase gene. Journal of virological methods. 2019;263:14-9.

[20] Tchesnokov EP, Feng JY, Porter DP, Götte M. Mechanism of inhibition of Ebola virus RNA-dependent RNA polymerase by remdesivir. Viruses. 2019;11:326.

[21] O'Hanlon R, Leyva-Grado VH, Sourisseau M, Evans MJ, Shaw ML. An Influenza Virus Entry Inhibitor Targets Class II PI3 Kinase and Synergizes with Oseltamivir. ACS infectious diseases. 2019;5:1779-93.

[22] Dutta K. Multi valent DNA vaccine against group A human rotavirus: an in-silico investigation. bioRxiv. 2020.

[23] Leon-Icaza SA, Zeng M, Rosas-Taraco AG. microRNAs in viral acute respiratory infections: immune regulation, biomarkers, therapy, and vaccines. ExRNA. 2019;1:1.

[24] Pruijssers AJ, Denison MR. Nucleoside analogues for the treatment of coronavirus infections. Current opinion in virology. 2019;35:57-62.

[25] Garimella T, Tao X, Sims K, Chang Y-T, Rana J, Myers E, et al. Effects of a fixeddose co-formulation of daclatasvir, asunaprevir, and beclabuvir on the pharmacokinetics of a cocktail of cytochrome P450 and drug transporter substrates in healthy subjects. Drugs in R\&D. 2018;18:55-65. 
[26] Toyota J, Karino Y, Suzuki F, Ikeda F, Ido A, Tanaka K, et al. Daclatasvir/asunaprevir/beclabuvir fixed-dose combination in Japanese patients with HCV genotype 1 infection. Journal of gastroenterology. 2017;52:385-95

[27] Ahmed AM, Doheim MF, Mattar OM, Sherif NA, Truong DH, Hoa PT, et al. Beclabuvir in combination with asunaprevir and daclatasvir for hepatitis $\mathrm{C}$ virus genotype 1 infection: A systematic review and meta-analysis. Journal of medical virology. 2018;90:907-18.

[28] Gentile I, Zappulo E, Buonomo AR, Maraolo AE, Borgia G. Beclabuvir for the treatment of hepatitis C. Expert opinion on investigational drugs. $2015 ; 24: 1111-21$.

[29] Hui DS, I Azhar E, Madani TA, Ntoumi F, Kock R, Dar O, et al. The continuing 2019-nCoV epidemic threat of novel coronaviruses to global health-The latest 2019 novel coronavirus outbreak in Wuhan, China. International Journal of Infectious Diseases. 2020;91:264-6.

[30] Huang C, Wang Y, Li X, Ren L, Zhao J, Hu Y, et al. Clinical features of patients infected with 2019 novel coronavirus in Wuhan, China. The Lancet. 2020.

[31] Corman VM, Landt O, Kaiser M, Molenkamp R, Meijer A, Chu DK, et al. Detection of 2019 novel coronavirus (2019-nCoV) by real-time RT-PCR. Eurosurveillance. 2020;25:2000045. 